\title{
O significado do trabalho para usuários de serviços de saúde mental inseridos em projetos de geraçáo de renda vinculados ou não ao movimento da economia solidária ${ }^{1}$
}

\author{
Isabela Aparecida de Oliveira Lussi ${ }^{\mathrm{a}}$, Giovana Garcia Morato ${ }^{\mathrm{b}}$

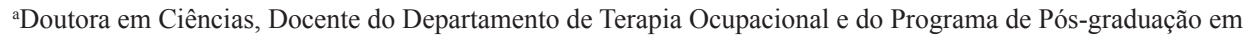 \\ Terapia Ocupacional, Universidade Federal de São Carlos - UFSCar, São Carlos, SP, Brasil \\ ${ }^{\text {b} T e r a p e u t a ~ O c u p a c i o n a l, ~ M e s t r a n d a ~ d o ~ P r o g r a m a ~ d e ~ P o ́ s-g r a d u a c ̧ a ̃ o ~ e m ~ T e r a p i a ~ O c u p a c i o n a l, ~}$ \\ Universidade Federal de São Carlos - UFSCar, São Carlos, SP, Brasil
}

\begin{abstract}
Resumo: Dentre os avanços decorrentes do processo da Reforma Psiquiátrica no Brasil, foi inaugurada, em 2004, uma parceria entre a Área Técnica de Saúde Mental do Ministério da Saúde e a Secretaria Nacional de Economia Solidária do Ministério do Trabalho e Emprego com o objetivo de fomentar as experiências de geração de renda na área de saúde mental. O presente estudo teve como objetivo identificar o significado do trabalho para os usuários de serviços da saúde mental participantes de projetos de geração de renda vinculados ou não ao movimento da economia solidária e adotou a abordagem de pesquisa qualitativa. Foram sujeitos deste estudo dois grupos, cada um composto por cinco usuários de serviços de saúde mental participantes de projeto de geração de renda, um grupo sem vínculo com o movimento da economia solidária e outro vinculado ao movimento. Os resultados apontam que, de acordo com a percepção dos participantes, o trabalho promove mudanças pessoais e sociais, é fonte de satisfação pessoal e estimula a construção de projetos de vida, além de contribuir na recuperação e possibilitar trocas materiais e sociais. A participação do usuário de saúde mental no movimento da economia solidária é uma experiência rica, pois possibilita o trabalho autogestionário, promove trocas de apoio, carinho e solidariedade. Acredita-se que estudos desenvolvidos nessa direção possam fornecer subsídios para a elaboração e implementação de políticas públicas que fomentem a geração de trabalho e renda, criando condições de ingresso ou retorno das pessoas que se encontram em desvantagem social ao mundo do trabalho.
\end{abstract}

Palavras-chave: Reabilitação, Saúde Mental, Trabalho.

\section{The meaning of work for users of mental health services included in income generation projects linked or not to the movement of solidarity economy}

\begin{abstract}
Among the advances resulting from the process of the Psychiatric Reform in Brazil in 2004, a partnership was started between the Mental Health Technical Division of the Ministry of Health and the Solidarity Economy National Secretary of the Ministry of Labor with the objective of promoting experiments of income generation in the field of mental health. The purpose of the present study was to identify the meaning of labor to the users of mental health services participating in projects of income generation, linked or not to the movement of solidarity economy. The qualitative research approach was adopted. The study comprised two subject groups, each one consisting of five users of mental health services participating in projects of income generation: one linked to the movement of solidarity economy and the other not linked to this movement. Results show that according to the perception of the participants, labor promotes personal and social changes, constitutes a source
\end{abstract}

Autor para correspondência: Giovana Garcia Morato, Universidade Federal de São Carlos, Rod. Washington Luís, Km 235, São Carlos, SP, Brasil, e-mail: giovana_morato@hotmail.com

Recebido em 13/6/2012; Revisão: 8/8/2012; Aceito em 13/9/2012. 
for personal satisfaction, and stimulates the construction of life projects, in addition contributing to recuperation and making social and material exchanges possible. The participation of the mental health user in the solidarity economy movement is a rich experience, because it facilitates self-managed labor and promotes exchange of support, affection and solidarity. It is believed that studies developed in that direction can provide subsidies to the elaboration and implementation of public policies that promote the generation of work and income, creating conditions for those people that find themselves in social disadvantage to be inserted or returned to the labor environment.

Keywords: Rehabilitation, Mental Health, Work.

\section{Introdução}

Dentre os avanços decorrentes do processo da Reforma Psiquiátrica brasileira, em 2004, foi inaugurada uma parceria entre a Área Técnica de Saúde Mental do Ministério da Saúde e a Secretaria Nacional de Economia Solidária do Ministério do Trabalho e Emprego com o objetivo de fomentar as experiências de geração de trabalho e renda na área de saúde mental (BRASIL, 2005a).

Para Cortegoso, Cia e Lucas (2008), a economia solidária é uma outra economia, que contrapóe-se ao capitalismo principalmente por conceber a possibilidade de geração de trabalho e renda para uma parcela da populaçáo que se encontra excluída da sociedade. Além disso, representa outra forma de produção e de organização da sociedade e mesmo da cultura. Os autores consideram como valores fundamentais da economia solidária,

[...] adesão voluntária e esclarecida dos membros, participação democrática em processos decisórios, autogestão, cooperação, intercooperação, promoção do desenvolvimento humano, preocupação com a natureza, preocupação com a comunidade, produçáo e consumo éticos, solidariedade (CORTEGOSO; CIA; LUCAS, 2008, p. 28).

Observa-se que algumas experiências recentes de inserção ou reinserção de pessoas com transtorno mental em atividades de trabalho têm ocorrido, no cenário nacional, pela via da economia solidária, por meio da participaçáo em empreendimentos econômicos solidários. Para Cortegoso, Cia e Lucas (2008), os empreendimentos econômicos solidários mais comumente conhecidos são as cooperativas.

Segundo Ghirardi (2004), cooperativas alicerçadas pelos princípios da economia solidária também têm-se apresentado como uma boa alternativa para a inclusão de pessoas que apresentam algum tipo de deficiência no mercado de trabalho. Para a autora,
[...] as cooperativas se constituem como empresas e não como um dispositivo terapêutico ou clínico. Essas empresas não se constroem dentro do modo de produção capitalista, mas sim a partir da proposta da economia solidária. Pensar o cooperativismo como alternativa possível para a inclusão social pela via do trabalho é aceitar o desafio de produzir uma intervenção transdisciplinar que, a partir da apropriação do conhecimento de diversas áreas, procure encontrar um lugar de existência para além do âmbito da saúde. Um espaço pautado pela lógica das trocas sociais e náo pela lógica do universo da saúde e da doença (GHIRARDI, 2004, p. 50).

Para Lancman (2007) há uma centralidade no papel do trabalho na vida das pessoas, funcionando como promotor da constituiçáo da identidade individual e, consequentemente, interferindo diretamente nas inserçôes sociais. Ele está ligado diretamente à formação das redes sociais dos indivíduos, a suas trocas afetivas e econômicas e, portanto, norteia a rotina de vida das pessoas. Para a autora, o trabalho alicerça o sentimento de pertencimento social.

O estudo de Lussi (2009) corrobora esta ideia quando constata, no relato dos sujeitos de sua pesquisa, que a concepção de trabalho está diretamente interligada ao resgate de sentimentos, de atitudes, de habilidades e de capacidades que anteriormente se viam apagadas. A autora pôde perceber que, na percepçáo dos sujeitos de sua pesquisa, o trabalho se configura como uma importante ferramenta para a emancipaçáo social deles, além de possibilitar o autoconhecimento e a autorrealização e permitir uma diminuição da ociosidade.

Porém, a autora identificou que os usuários da saúde mental que experimentam práticas de autogestão e processos de decisão democrática no ambiente de trabalho mostraram ter autonomia maior em relação ao trabalho que desenvolvem, bem como 
em relação à própria vida, do que usuários que não experimentam esse tipo de prática (LUSSI, 2009).

Para Pacheco (2008), o trabalho autogestionário cria condições de ampliação da inclusão social de usuários da saúde mental e isto ocorre por meio da participação no movimento da economia solidária. $\mathrm{O}$ autor pontua que a experiência de participação na rede de economia solidária é rica e promove trocas de apoio, carinho e solidariedade, sem discriminação, além de proporcionar o exercício da autogestão.

O estudo realizado por Lussi (2009) apontou a importância de se considerar a opinião dos atores sociais diretamente comprometidos com os processos de inserção social, isto é, as concepções dos usuários de serviços de saúde mental sobre o lugar ocupado pelo trabalho em tais processos. Ressalta-se a relevância dessas concepçóes na proposição de políticas públicas voltadas à geração de trabalho e renda aos usuários, bem como no planejamento de projetos de inclusão social por meio do trabalho.

Acredita-se que estudos desenvolvidos nessa direção possam fornecer subsídios para a elaboração e implementação de políticas públicas que fomentem efetivamente a geração de trabalho e renda, criando reais possibilidades de ingresso ou retorno das pessoas que se encontram em situação de desvantagem social ao mundo do trabalho.

O presente estudo propõe-se a contribuir investigando o significado do trabalho para usuários de serviços de saúde mental participantes de projetos de geraçấo de renda vinculados e náo vinculados ao movimento da economia solidária.

\section{Metodologia}

Diante da constatação de que o campo da saúde mental contempla uma gama de significados e sentidos complexos que são socialmente construídos, o presente estudo adotou a abordagem de pesquisa qualitativa, considerando esta a mais adequada para o alcance dos objetivos traçados. Tal abordagem é condizente com o processo de análise de dados que deve ser concebido sob a ótica de uma dada realidade histórica e apreendido a partir da interpretação feita por seus atores.

O presente estudo se efetivou a partir da escolha de dois locais nos quais se desenvolvem projetos de geração de renda para a coleta de dados, um deles vinculado ao movimento da economia solidária e o outro não vinculado ao movimento. Assim, os locais escolhidos foram:

- O empreendimento econômico solidário RECRIART, ligado ao Centro de Atenção
Psicossocial (CAPS) da Secretaria Municipal de Saúde de São Carlos e à Incubadora Regional de Cooperativas Populares (INCOOP/UFSCar); e

- O Núcleo de Oficinas e Trabalho (NOT) do Serviço de Saúde Dr. Cândido Ferreira do município de Campinas.

Ambos os municípios se localizam no interior do estado de Sáo Paulo.

Foram sujeitos deste estudo 10 usuários de serviços de saúde mental participantes desses dois projetos, sendo 5 de cada um deles. Os critérios de seleção basearam-se na disponibilidade para os indivíduos participarem da pesquisa e na indicação da equipe conforme os critérios: condição clínica estável e favorável à participação.

Das informações coletadas no protocolo preliminar de informações pessoais e profissionais dos participantes constata-se que 3 participantes $\mathrm{da}$ presente pesquisa são do sexo feminino e 7 , do sexo masculino. A média de idade é 42 anos. Quanto ao estado civil, 3 são solteiros, 4 são casados, 1 é divorciado, 1 é desquitado e 1 é viúvo.

Em relação à profissão, foi possível identificar grande variedade entre os participantes, como mostra o Quadro 1:

Quadro 1. Profissão dos participantes.

\begin{tabular}{|l|c|}
\hline \multicolumn{1}{|c|}{ Profissão } & Número de citação \\
\hline Babá & 1 \\
\hline Cuidador de pessoas doentes & 1 \\
\hline Faxineira & 1 \\
\hline Auxiliar de acabamento & 1 \\
\hline Serviços gerais & 3 \\
\hline Vidraceiro & 1 \\
\hline Vigilante & 1 \\
\hline Auxiliar de produção & 1 \\
\hline Mosaicista & 1 \\
\hline Serralheiro & 1 \\
\hline
\end{tabular}

Nota-se pelo Quadro 1 que alguns participantes citaram mais de uma profissão.

Quanto às atividades que os sujeitos da pesquisa estavam realizando em seu local de trabalho nos projetos de geração de renda durante o período da coleta de dados, encontrou-se:

- Reciclagem de papel; confecção de produtos derivados do papel reciclado tais como blocos, porta-retratos, crachás, marcadores de livros etc.;

- Colagem e acabamento dos produtos anteriormente citados; 
- Limpeza de cuba de confecção de papel reciclado;

- Manuseio de guilhotina;

- Vendas de produtos na praça;

- Cultivo de hortaliças e manuseio geral de horta;

- Desenho e lixamento de peças na serralheria;

- Solda e policorte na serralheria; e

- Confecção de mosaico.

Foi possível constatar que a maioria dos participantes do presente estudo não desenvolviam trabalhos relacionados à sua profissão anterior. Um dos sujeitos considerou como sua profissão o trabalho que desenvolvia no momento da coleta, mesmo tendo informado no protocolo de informaçôes pessoais e profissionais que já tinha exercido a função de montador de pizza, forneiro e vigia antes de começar a trabalhar na oficina, e outro participante afirmou que o trabalho que desenvolvia na atual oficina era o mesmo que exercia antes de frequenta-la.

Em relação ao tempo de participação nas oficinas ou empreendimento econômico solidário foi possível constatar uma grande variação: 1 sujeito participava há 21 anos, 1 há 5 anos, 3 há 4 anos, 1 há 2 anos, 1 há 1 ano e 3 há 5 meses.

Para a coleta de dados, primeiramente o projeto foi submetido ao Comitê de Ética em Pesquisa em Seres Humanos da UFSCar, tendo sido aprovado sob o parecer n. 200/2011. Após sua aprovação iniciou-se o trabalho de campo. Para a localizaçáo dos participantes foram realizados contatos com as coordenações do NOT e do RECRIART. Após os esclarecimentos sobre os objetivos da pesquisa foi solicitada autorização para a sua realização junto aos usuários dos dois contextos. Foi solicitado que as equipes indicassem usuários da saúde mental que estivessem frequentando as oficinas ou o empreendimento de geração de renda e que a equipe julgasse estarem em condição clínica favorável e estável para participar da pesquisa. Após a indicação, os sujeitos foram contatados e consultados sobre o desejo de participar ou náo da pesquisa, tendo liberdade de escolha para tal. Para aqueles que aceitaram participar foi solicitado que assinassem o Termo de Consentimento Livre e Esclarecido - TCLE.

Os dados foram coletados a partir da utilizaçáo da técnica de entrevista. Considerou-se a entrevista semiestruturada como a mais adequada para este estudo, pois, como coloca Minayo (2000), combina questóes estruturadas e abertas por meio das quais o sujeito pode discorrer livremente sobre o tema proposto sem se ater a condições e questôes pré-estabelecidas pelo entrevistador. A aplicação da entrevista ocorreu em locais e horários previamente combinados entre pesquisador e os participantes $\mathrm{da}$ pesquisa no RECRIART. No NOT, esse acordo foi intercambiado pela equipe responsável, que se prontificou a agendar dia e horário com os sujeitos que aceitaram participar e repassar para a pesquisadora.

O roteiro para a entrevista foi preparado baseado no objetivo da pesquisa e em referencial bibliográfico da área. Abordou elementos sobre o significado e efeitos do trabalho para os sujeitos; os efeitos de ficar sem trabalhar para sua vida; as diferenças entre o trabalho realizado atualmente e os realizados anteriormente; e o contexto do trabalho atual (se gosta, quais atividades realizam, facilidades e dificuldades do trabalho, dinâmica da tomada de decisóes no grupo, contato com outros grupos de geraçâo de renda etc.).

Para a análise dos dados, utilizou-se a técnica de análise temática, cuja aplicação pressupóe a descoberta dos núcleos de sentido contidos na comunicação na qual a presença ou frequência de aparição desses pode revelar algum significado para o objetivo analítico eleito (BARDIN, 2008). Para a ordenaçáo dos dados obtidos por meio das entrevistas, elas foram transcritas em sua íntegra. Em seguida, foi feita a padronização das transcriçóes de modo que todas as entrevistas foram ordenadas, pelos dados de identificação pessoal e profissional, com os registros do diário de campo. Após tal ordenação das entrevistas foi realizada leitura exaustiva buscando-se uma apreensão global das mesmas, dos seus aspectos dinâmicos e interativos. Em seguida, buscou-se a identificação dos temas significativos ou das unidades de significação, utilizando-se os objetivos pré-estabelecidos como pano de fundo. Na sequência foi realizada a agregação dos temas, elaborando-se a grelha de categorias.

\section{Resultados e discussão}

A partir do conteúdo das falas dos sujeitos acerca do significado do trabalho para eles surgiram temas que foram agregados e dos quais emergiram as seguintes categorias:

- O trabalho como meio de satisfação pessoal e promotor de possibilidades;

- (Re) Estabelecimento da saúde mental: o trabalho como ferramenta no processo de recuperação;

- Componente do cotidiano: o trabalho como meio de combater o ócio; 
- O trabalho como potencializador de poder aquisitivo e da independência; e

- O trabalho viabilizando e ampliando as relaçóes sociais.

Para melhor compreensão do leitor, optou-se pela identificação, nas falas dos sujeitos, do projeto ao qual está vinculado. Dessa forma, o projeto vinculado ao movimento da economia solidária foi identificado pela sigla VES e o não vinculado a este movimento foi identificado pela sigla NVES.

\section{O trabalho como meio de} satisfação pessoal e promotor
de possibilidades

Durante as entrevistas e por meio das falas dos sujeitos foi possível detectar que o trabalho assume determinadas centralidades na vida deles, posto muitas vezes como promotor de possibilidades e como meio de satisfação pessoal.

Essa conotação atribuída ao trabalho pelos sujeitos da presente pesquisa pode ser melhor apreendida quando se analisa a afirmação feita por Tolfo e Piccinini (2007, p. 40):

O trabalho é rico de sentido individual e social, é um meio de produção da vida de cada um ao prover subsistência, criar sentidos existenciais ou contribuir na estruturação da identidade e da subjetividade.

Além disso, a forma por meio da qual o indivíduo vivencia e expressa o significado do trabalho em sua vida está relacionada às correntes filosóficas do momento histórico e, portanto,

[...] o sentido do trabalho, por sua atribuição psicológica e social, varia, na medida em que deriva do processo de atribuir significados e se apresenta associado às condições históricas da sociedade. É um construto sempre inacabado. (TOLFO; PICCININI, 2007, p. 40).

Foi possível verificar em alguns relatos dos sujeitos participantes do presente estudo o potencial do trabalho na direção de produção de vida, como mostra a fala abaixo:

Ai eu tenho muita vontade de trabalhar sabe, construir vida, fonte, de progredir né... conseguir fazer alguma coisa... que melhore né [...] uma realização também, a gente acaba se realizando né numa coisa que a gente tem vontade né. (S2 VES)
O estudo de Cayres et al. (2001, p. 107) aponta o crescimento pessoal impulsionado pelo trabalho quando atesta que

[...] através da oportunidade de trabalhar e ganhar pelo trabalho a pessoa recupera a possibilidade de ampliar seus conhecimentos, suas reflexóes, transformar suas açóes ou modificá-las diante das necessidades.

Foi possível identificar nas falas dos sujeitos, descritas abaixo, como o trabalho foi transformador da vida deles, evidenciando seu potencial de aprendizagem:

Eu sempre falo que lo trabalho que desenvolve atualmente na oficina] mudou a minha vida em $100 \%$ entendeu? Eu era usuário de cocaina, a partir do momento que eu entrei aqui faz cinco meses que eu estou limpo [...] (S10 NVES)

É, é um trabalho totalmente diferente né [quanto à diferença entre este trabalho e os que fez anteriormente]. É, porque evidencia a gente, então a gente aprende muita coisa né, porque através deste trabalho aqui eu já consegui assim, vários diplomas sabe... como plantio, adubação verde, atendimento ao cliente você entendeu, eu tenho alguns diplomas que foram tirados aqui em benefício desse trabalho da gente né... [...] Pra mim o... o significado desse trabalho, significa pra mim assim... uma reintegração, voltar a ser o que eu era antes né, no caso eu conseguir uma firma, você entendeu [...] (S7 NVES)

Há uma característica bastante marcada que aparece na fala de dois sujeitos que estão inseridos em projeto de geração de renda vinculado à economia solidária quando questionados sobre a diferença entre o trabalho que desenvolvem no momento, no empreendimento, e o que já realizaram antes. Tanto na fala de S1 quanto na de S2 aparece a questão do trabalho coletivo, da ajuda mútua, da divisão entre todos e da solidariedade, como expresso abaixo:

Esse daqui é. É diferente porque esse daqui é em grupo que a gente trabalha né, ai divide, tipo assim, o que você faz, você não faz pensando só pra você né, você trabalha em conjunto, então o que você ganha você divide com os outros né, então o pouquinho que você ganha é dividido, então eu acho muito legal isso (S2 VES)

É, é diferente e eu adoro demais [...] Ah, é diferente porque ali são todos amigos, são todos unidos né, a gente conversa, bate papo, um ajuda o outro né? Então pra mim é mais importante esse trabalho agora de todos os que eu já fiz (S1 VES) 
Foi possível perceber nos relatos descritos acima a importância que os sujeitos atribuem às características do trabalho desenvolvido relacionadas aos princípios da economia solidária e que retomam a questão da satisfação pessoal, da realização e da percepção de um trabalho mais humano, como discutido anteriormente.

Segundo Brasil (2007), os dez princípios norteadores da economia solidária são: autogestão; democracia; cooperação; centralidade do ser humano; valorização da diversidade; emancipação; valorizaçâo do saber local; valorização da aprendizagem; justiça social na produção, comercialização, consumo e financiamento; e desenvolvimento tecnológico e cuidado com o meio ambiente.

De acordo com Singer (2002) o fato de a economia solidária sustentar valores como, por exemplo, o direito à liberdade de cada um, e propor meios de organização de trabalho diferenciados dos propostos pelo sistema capitalista como, por exemplo, a autogestão, gera, naturalmente, uma relação entre as pessoas marcada pela solidariedade e pela igualdade. Além disso, Singer (2008, p. 290) considera que "[...] o trabalho é uma forma de aprender, de crescer, de amadurecer, e essas oportunidades a economia solidária oferece a todos, sem distinção", evidenciando, assim, o potencial para transformaçôes e mudanças na vida de pessoas que trabalham nos moldes dessa economia.

A importância dos princípios da economia solidária em estratégias de intervenção no campo da saúde mental, como apontada nos relatos descritos acima, se justifica ante a análise da natureza do movimento da Reforma Psiquiátrica e da natureza da economia solidária. Assim, tem-se:

[...] os movimentos da Reforma Psiquiátrica e da Economia Solidária compartilham princípios fundamentais quando fazem a opção ética, política e ideológica por uma sociedade marcada pela solidariedade. É somente no ano de 2004, no entanto, que esses movimentos passam a se encontrar, a se reconhecer e a dialogar, iniciando uma colaboração permanente entre esses campos e entre os integrantes dos movimentos sociais correspondentes, tendo como desafio a reinserção social de egressos de manicômios por meio da construção de empreendimentos solidários e autogestionários (BRASIL, 2005b, p. 34).

A afirmaçáo feita por Delgado (2005) contribui nesta discussáo. Para o autor existe uma relaçáo de cooperação entre os dois movimentos que é inevitável, já que ambos se propóem à mudança da sociedade no que diz respeito a maior generosidade dela, de forma a torna-la mais inclusiva e solidária. Além disso, para o autor, a economia solidária e o movimento antimanicomial brotam de uma mesma matriz que é a luta contra a exclusão social e econômica.

\section{5 (Re) Estabelecimento da saúde mental: o trabalho como ferramenta no processo de recuperação}

Para alguns sujeitos participantes da pesquisa, o trabalho é concebido como sinônimo e/ou meio de tratamento, recuperaçáo e até mesmo cura. Segundo Ogawa (1997), a ideia de que o trabalho é terapêutico tem sido largamente usada na história da psiquiatria para a reabilitação de pessoas com transtorno mental, inclusive consolidando-se, por meio de justificativas teóricas e várias experiências práticas. Silva (2005) complementa esta afirmação na medida em que afirma ser possível identificar nas propostas de terapias como, por exemplo, a laborterapia, a ergoterapia e mesmo na perspectiva do trabalho assistido a permanência de uma ideologia instituída pelos manicômios que é a ideia de que o trabalho cura.

Nas falas de alguns sujeitos do presente estudo pode-se identificar a atribuiçáo de caráter terapêutico ao trabalho:

Aqui eu me sinto assim, que eu venho para uma terapia né. Pra ajudar a desenvolver a minha mente [...] (S2 VES)

[...] é como se fosse uma terapia né, não tem nada a ver com... com trabalho, então eu encaro mais como uma terapia (S4 VES)

Aqui eu tô fazendo a terapia, tem hora que dá uns desânimos em mim e eu tenho que ficar fazendo as coisas pra... pra distrair sabe, pra poder ajudar, pra mim não ficar doente (S5 VES)

[...] aqui é, tipo assim, uma recuperação que é o NOT, que é o serviço de oficinas terapêuticas (S7 NVES)

Foi possível constatar, quase que em unanimidade entre os sujeitos vinculados ao movimento da economia solidária, a concepção do trabalho sob um enfoque terapêutico. Na verdade, esses sujeitos trazem essa relaçáo de maneira mais explícita ao utilizarem o termo terapia como equivalente ao trabalho, o que não apareceu da mesma maneira na fala dos sujeitos náo vinculados ao movimento da economia solidária, embora um número menor 
de sujeitos também tenha considerado o trabalho sob um enfoque terapêutico.

Esse resultado refuta uma das hipóteses deste estudo, pois se esperava que os usuários vinculados ao movimento da economia solidária apresentassem maior apropriação do trabalho desenvolvido devido, principalmente, ao exercício da autogestão no âmbito do empreendimento e, consequentemente, minimização do enfoque terapêutico atribuído ao mesmo.

A diferença encontrada entre os dois grupos suscita reflexôes acerca da concepção de trabalho de cada um, e mesmo a investigação das razóes que levam determinados indivíduos a esboçar mais incisivamente uma tradição psiquiátrica que concebia o trabalho como terapia.

É necessário considerar as diferenças individuais de cada sujeito da pesquisa, já que a maneira de conceber o trabalho sob enfoque terapêutico pode estar relacionada ao perfil intelectual de cada um, à condição do quadro clínico atual e mesmo à habilidade para elaborar essa concepção. Muito embora essa investigação não tenha sido um objetivo estabelecido inicialmente para a presente pesquisa, é certamente uma questáo relevante que caminha em direção a uma leitura mais fidedigna dos dados sem generalizá-los.

Na concepção de Lussi e Pereira (2011), quando os usuários da saúde mental vivenciam experiências laborais que de fato os remetem a um contexto de trabalho e possibilitam a eles vivenciar trocas materiais, sociais e afetivas, fazendo com que sintam-se participantes da vida social, essa vivência viabiliza a mudança de concepção de trabalho terapêutico para trabalho com sentido, significado e valor social.

Outra maneira de analisar a dimensão dada ao trabalho por alguns sujeitos da pesquisa pode vincular-se ao fato de ele ser realizado nas dependências de um equipamento de saúde, ou estar ligado a um equipamento desse tipo, destinado ao tratamento de pessoas com transtornos mentais.

Além dessa possibilidade, o fato de o grupo de pessoas que compóe as oficinas/o empreendimento ser homogêneo, ou seja, composto somente por usuários de serviços de saúde mental, pode reforçar essa concepção. Neste sentido, é pertinente a discussão quanto à viabilidade do uso de cooperativas integradas na área da saúde mental, posto que representam um mecanismo alternativo por meio do qual é possível converter o trabalho terapêutico e institucionalizado em trabalho que produz sentido e valor (SARACENO, 2001a). Além disso, por meio das cooperativas integradas tem sido possível criar formas mais autônomas de trabalho e novas maneiras de organização do trabalho com o objetivo de atingir uma população que se encontra em desvantagem (SARACENO, 2001a).

Argumenta-se que as cooperativas ou associaçôes devem ser compostas por pessoas com transtornos mentais e outras que não estejam nesta condição.

\section{Componente do cotidiano: o trabalho como meio de combater o ócio}

Foi possível observar nos relatos de grande parte dos sujeitos menções quanto ao trabalho como sinônimo de ocupação. Há, no entanto, a presença da palavra ocupação sob duas designaçōes: 1) a ocupação como distração, uma forma de afastar maus pensamentos ou evitá-los; e 2) a ocupação como meio de preencher o tempo, o espaço livre do dia, nortear o cotidiano e evitar o ócio. Entretanto, foi possível identificar que embora sejam "ocupaçóes" de natureza diferente (da mente/da cabeça e do espaço/do tempo) que levam a compreensôes distintas, essas duas designaçóes muitas vezes apareceram de forma complementar, além de aparecerem isoladamente.

Nas falas descritas abaixo, é possível apreender que os sujeitos significaram ocupaçáo com o primeiro sentido, ou seja, relativo à mente, à distração e ao afastamento de pensamentos:

[trabalho] é uma... ocupação né, pra minha cabeça. Aí distrai né? Você se sente ocupado com alguma coisa interessante né, então... (S2 VES)

\section{[...] me distrai bastante também e pra mim trabalho ajuda a [...] passar o dia, assim, sem pensar nos problemas, da, da, da vida da gente né, e pra mim isso é um... é muito bacana o trabalho (S8 NVES)}

[...] ajuda muito a gente esquecer, a gente se acalmar, a gente ficar pensando no que a gente está fazendo [...] (S5 VES)

O significado do trabalho como ocupação retoma, de certa forma, o preceito de que se ocupa a mente para ficar bem, para afastar maus pensamentos e, consequentemente, preservar a saúde mental. O estudo de Lussi (2009) constatou na fala dos sujeitos de sua pesquisa esta mesma conotação dada ao trabalho.

O estudo realizado por Rodrigues, Marinho e Amorim (2010) também identificou na fala dos 
sujeitos este sentido atribuído ao trabalho. Para os sujeitos do referido estudo:

[...] o trabalho é interpretado como um recurso importante de proteção contra recaídas e crises, possível através da ocupação da mente e do tempo. Os participantes narram a necessidade de estar em atividade, a fim de substituir preocupaçóes ou pensamentos negativos (RODRIGUES; MARINHO; AMORIM, 2010, p. 1620).

A fala dos sujeitos descrita abaixo ilustra o segundo sentido para ocupação:

Ah eu adoro participar porque... [...] você tem então com o que se ocupar você entendeu? E a gente parado em casa não tem com o que se ocupar, a gente já vai procurar outras coisas então eu me sinto bem (S7 NVES)

Ah, pra mim é importante [o trabalho] né, porque não fico em casa né, o dia inteiro assim [...] (S9 NVES)

[ficar sem trabalhar] [...] é horrivel né, porque a gente levanta da cama e não tem o que fazer [...] (S7 NVES)

$\mathrm{Na}$ fala dos sujeitos supracitados, o trabalho parece ser concebido como parte do cotidiano, pois o expressam como algo que garante a eles não permanecer em casa o dia todo sem fazer nada.

Saraceno (2001a, p. 116) considera que o cotidiano das pessoas é composto de vários elementos que vão desde o autocuidado até a questáo do exercício do trabalho e, portanto, "[...] tudo isso é a nossa vida cotidiana, a grandiosa banalidade de viver, trocando afetos e mercadorias".

No relato dos sujeitos, a ocupação atribuída como significado do trabalho parece impedi-los de se apropriar desse trabalho e de desfrutar das oportunidades que ele pode proporcionar. É importante refletir sobre os motivos que impedem a ampliação do significado do trabalho, para os sujeitos, para além de mera ocupação.

\section{O trabalho como}

\section{potencializador de poder aquisitivo e da independência}

Foi possível constatar no relato dos sujeitos que o trabalho, para alguns, é o meio pelo qual se obtém renda, se pode ter dinheiro, expressando uma forma de prover as necessidades materiais, como mostram os depoimentos:
Ah, trabalho pra mim é uma forma de, de gerar renda. [...] o ser humano náo vive sem trabalho, sem uma renda, então pra mim é isso (S4 VES)

Trabalho é um... pra mim é, além de ser uma coisa necessária para ajudar na despesa da minha casa né [...] a gente precisa de trabalhar por causa do pouco que a gente recebe (S8 NVES)

Percebe-se que o trabalho está associado à geração de renda, sendo, inclusive, concebido como necessário para o complemento da renda familiar. Há a constatação dessa evidência na fala de S8 supracitada, bem como em ambos os grupos notou-se a relação entre o ser humano e o trabalho como um vínculo indissociável, como no relato de S4, que sustenta a ideia de que o homem náo vive sem trabalho, sem uma renda.

De acordo com Silva e Fonseca (2002, p. 363), "[...] o processo de produção de vida material, na sua dimensão social, efetiva-se pelo trabalho".

Uma outra verificação possível é a de que, para além de apenas gerar renda, o trabalho assume um valor simbólico vivenciado pelo indivíduo, que o traduz como independência tanto pessoal quanto financeira. Na realidade, esse sentido para o trabalho surgiu nos relatos dos sujeitos quando foram questionados quanto a ficar sem trabalhar. Assim, identificam que estar sem trabalhar faz com que se sintam dependentes, como se verifica nas falas abaixo:

Ah é muito ruim porque aí você depende $d a$, da família né, família tem que te ajudar até você... você achar outro emprego né (S4 VES)

[...] então você tem que estar dependendo de outras pessoas, e você trabalhando você vira uma pessoa independente não é isso? (S7 NVES)

O estudo realizado por Rodrigues, Marinho e Amorin (2010) aponta que o trabalho, para os sujeitos, vem significado a partir da possibilidade de conquistar autonomia e independência e, consequentemente, de adquirir independência econômica e mesmo moral em relação à família.

Nessa direçấo, o estudo realizado por Tagliaferro (2011) aponta que, na percepção de integrantes da equipe de incubação de um empreendimento de economia solidária de usuários da saúde mental, esses usuários têm assumido, por meio do trabalho, mais responsabilidades, o que influencia na forma como a família passa a vê-los, ou seja, passam a assumir outro papel na família, deixando de ser vistos como doentes e passando a ser reconhecidos como trabalhadores. 
Outro aspecto identificado no estudo de Rodrigues, Marinho e Amorin (2010) é que, quando os indivíduos percebem que são capazes de contribuir nas despesas de casa e no cuidado de suas próprias necessidades parecem esboçar um sentimento de utilidade, além disso, o retorno financeiro oriundo do trabalho faz com que o sujeito seja capaz de prover suas necessidades, o que acaba por lhe conferir maior autonomia.

É possível refletir quanto às possibilidades de conquista de autonomia e mesmo de uma melhor desenvoltura quando é dado aos sujeitos a oportunidade de uma expansão de suas habilidades por meio de oferta de responsabilidades e atividades extra oficinas/empreendimento. Nesse sentido, parece que os sujeitos vinculados à economia solidária vivenciam esta condição com uma intensidade maior. Isso certamente faz com que esses sujeitos tornem-se aos poucos cada vez mais autônomos e cada vez mais protagonistas de suas açốes no contexto de trabalho. $\mathrm{O}$ exercício desse protagonismo bem como a possibilidade de acesso a outros equipamentos sociais podem ser concebidos como molas propulsoras para a inclusão social, bem como para o resgate da cidadania desses sujeitos.

\section{0 trabalho viabiliza e amplia as relações sociais}

A partir da fala dos sujeitos pode-se constatar que o trabalho facilita as relaçôes sociais para eles. Isso aparece à luz de duas condiçôes: a primeira é que trabalhar permite o contato com amigos bem como fazer novas amizades, o que influencia de maneira positiva na saúde mental; a segunda é que ficar sem trabalhar faz com que haja um afastamento dos amigos e, portanto, uma diminuição dessas relaçôes, bem como um distanciamento das redes sociais. Essas constatações evidenciam-se nos relatos abaixo.

Quanto à primeira questão:

Eu me sinto muito bem [trabalhando] tá? Mais tranquilo, sossegado, tenho um bom relacionamento com a chefia, com meus amigos de trabalho, então isso tudo influi na capacidade e na presença da gente né [...] (S7 NVES)

\section{[...] Agora, graças a Deus por causa da geração de renda, com os amigos, com os companheiros, eu estou me sentindo muito bem de frequentar aqui a geração de renda, é muito importante para mim (S5 VES)}

[...] ali vocêfaz amizade às vezes com pessoas que tem problema que nunca, nunca tinha convivido com pessoas assim né, hoje, hoje já sabe como lidar com essa pessoa né (S8 NVES)

Foi possível identificar na fala dos sujeitos que estar trabalhando faz com que novas amizades surjam. Ficou evidente também que o ambiente de trabalho permitiu a um dos sujeitos aprender a lidar com as diferenças, o que denota uma ampliação da capacidade relacional do indivíduo.

Em relação à possibilidade de novos contatos e às boas relações que se podem estabelecer em ambientes de trabalho, Barfknecht, Merlo e Nardi (2006) puderam constatar em sua pesquisa que foi de extrema importância para os trabalhadores de uma cooperativa alicerçada nos princípios da economia solidária vivenciar o trabalho coletivo, compartilhar o espaço de trabalho e novas maneiras de produzir com os colegas, realizar essas trocas de saberes e, principalmente, essa expansão nas relaçóes sociais viabilizadas.

O resultado encontrado na pesquisa de Barfknecht, Merlo e Nardi (2006) quanto às relaçóes sociais no trabalho está em consonância com o da pesquisa de Milioni (2009), na medida em que, segundo a autora, os sujeitos avaliam como positiva a experiência do trabalho - contextualizado em um empreendimento de economia solidária - já que, para eles, estar inserido nesse contexto de trabalho viabiliza a construção de novas relaçóes cujo resultado é o sentimento de conforto, de segurança, bem como de pertencimento a um grupo, o que traz satisfação e bem-estar.

Discutir de que maneira as relaçóes no trabalho influenciam a vivência do indivíduo tanto no trabalho quanto em sua vida cotidiana e certamente, em sua saúde mental, é imprescindível, já que essas relaçôes podem ser pensadas como mecanismos que respaldam os sujeitos em seu processo de reabilitação. Logo, sob essa perspectiva, os sujeitos parecem evindenciar que as boas relaçôes no trabalho viabilizam a manutenção de suas condiçóes de saúde mental. Dentro desta discussão é importante ressaltar que ambientes de trabalho caracterizados por princípios da economia solidária tendem a potencializar as qualidades impressas por boas relações sociais já que os valores inerentes à economia solidária viabilizam um maior contato entre os sujeitos, que vem marcado pela solidariedade, igualdade e trocas tanto sociais quanto materiais.

Os relatos descritos abaixo mostram como o distanciamento do trabalho afeta as relaçóes sociais.

Olha, na verdade eu senti falta dos amigos Lquando esteve sem trabalhar] (S10 NVES) 
Ah, eu senti falta do serviço, das amizades, das patroas né (risos), das conversas delas, a gente batia papo... e a gente ficar sem trabalhar fica em casa muito sozinha, é ruim, não tem com quem falar, fica muito só (S1 VES)

[quando esteve sem trabalhar] Ah, dos amigos entendeu, porque tinha muita amizade, tinha uns encarregados sabe, tinha mui, mui, muitos amigos lá que gostavam de mim, en gostava deles, eles davam as coisas pra mim sabe, presente [...] (S5 VES)

A fala dos sujeitos supracitada deixa transparecer uma espécie de ruptura nas relaçóes sociais quando se encontram excluídos do universo do trabalho. Isso fica bastante evidente na fala de $S 1$.

A constatação de que as relaçôes sociais se ampliam por meio do trabalho, bem como as possibilidades de troca, fica evidente nos relatos dos sujeitos quando eles, ao falarem sobre suas atividades, além das desenvolvidas dentro das oficinas/empreendimento de geração de renda, ressaltam o contato que acabam tendo com outras pessoas, para além daquelas do convívio diário do contexto de trabalho, quando em contextos de comercializaçáo ou divulgação dos produtos, por exemplo.

Nessa direção, Saraceno (2001b, p. 151) considera que,

[...] a pré-condição das relaçôes entre as pessoas é a troca, é o negócio, ou seja, o negócio precede o ócio. Dito de outra maneira, as oportunidades de trocas materiais e simbólicas são oportunidades precedentes na construção da capacidade relacional do sujeito.

De forma complementar, pode-se dizer que somente quando o indivíduo tem, de fato, o direito de exercitar plenamente trocas materiais e afetivas por meio da participação no mercado está sendo dado a ele o direito às relaçóes sociais (SARACENO, 2001a).

É possível identificar que, embora os sujeitos dos dois grupos participantes da pesquisa deixem transparecer, por meio de suas falas, uma ampliação nas relaçôes, bem como um maior contato com as pessoas por meio de atividades extra oficina/ empreendimento, como quando vão às feiras, pôde-se constatar uma ênfase dada pelos sujeitos inseridos em projetos de geração de renda não vinculados à economia solidária ao maior contato com pessoas de outras oficinas, porém frequentadores do mesmo ambiente. Já na fala dos sujeitos inseridos em projetos de geração de renda vinculados à economia solidária, pôde-se perceber que há maior contato com pessoas de outros empreendimentos, inclusive não usuários da saúde mental, contatos, portanto, fora do contexto desses sujeitos.

Parece que para os sujeitos da pesquisa vinculados ao movimento da economia solidária as relaçóes se estendem de maneira que eles têm a possibilidade de estar em contato maior com o cotidiano e o dia a dia de pessoas que não são usuários da saúde mental e, portanto, têm a oportunidade de se aproximar de realidades que se diferenciam bastante de sua vivência, muitas vezes dramática e restrita: as realidades daqueles que por vezes os estigmatizam em consequência de serem usuários da saúde mental.

Isso certamente contribui para que esses sujeitos se aproximem de outros cotidianos, outras realidades, bem como faz com que se sintam parte do universo das relaçóes e das trocas, do qual por vezes se sentem excluídos.

\section{Considerações finais}

O presente estudo teve como objetivo identificar o significado do trabalho para os usuários de serviços de saúde mental participantes de projetos de geração de renda vinculados e náo vinculados ao movimento da economia solidária.

A realização da presente pesquisa permitiu a confirmaçáo de apontamentos encontrados na literatura quanto à importância e viabilidade do uso do trabalho no processo de reabilitação de usuários de serviços de saúde mental.

Utilizando como pano de fundo o objetivo desta pesquisa, os conteúdos da fala dos sujeitos autorizam afirmar que o trabalho representa, de fato, um importante instrumento no processo de ressocialização e inclusão desses sujeitos. Além disso, os participantes apontaram o trabalho como promotor de possibilidades e meio de obter satisfação pessoal. $\mathrm{O}$ trabalho apareceu, ainda, como um instrumento importante no processo de recuperação desses sujeitos, como uma oportunidade para conquista de autonomia e independência, além de um meio pelo qual se constroem e ampliam relaçôes sociais.

Apesar dos incontestáveis aspectos positivos relacionados ao uso do trabalho no campo da saúde mental, foi possível constatar que os projetos de geração de renda estudados, caracterizados por oficinas de geraçáo de renda e empreendimento econômico solidário são, muitas vezes, percebidos pelos sujeitos como mais um dispositivo de tratamento. Muitos sujeitos concebem o atual trabalho realizado em oficina/empreendimento sob um enfoque terapêutico, evidenciando dificuldade para desfrutar os valores sociais que o trabalho 
pode oferecer. Entretanto, relatam beneficiar-se da organizaçáo e dinâmica propostas, principalmente porque se torna um espaço privilegiado para a construção e/ou ampliação das relaçôes sociais.

Foi possível constatar que muitos sujeitos não incorporam o papel de trabalhador, alguns designam a oficina/empreendimento como local de trabalho mas não incorporam o papel de trabalhador. Essa constatação evidencia a necessidade de se rediscutir as propostas de trabalho e os formatos dessas propostas para os usuários de serviços de saúde mental, a fim de que eles incorporem, de fato, tal papel e se apropriem de seu ofício bem como se beneficiem dos valores provenientes do trabalho. É necessário buscar constantemente a desconstrução da visão de cura pelo trabalho para que se possa planejar projetos de inserção laboral que cumpram com os preceitos da reabilitação psicossocial e que de fato representem uma via de acesso à cidadania.

Argumenta-se que, apesar dos benefícios provenientes dos projetos de inserção laboral de usuários de serviços de saúde mental, são necessárias constantes atualizaçôes e discussóes quanto à temática do trabalho e a maneira de sua proposiçáo para que, de fato, ele promova mudanças sociais e a inclusão social.

\section{Referências}

BARDIN, L. Análise de conteúdo. 5. ed. Lisboa: Ediçôes 70, 2008.

BARFKNECHT, K. S.; MERLO, A. R. C.; NARDI, H. C. Saúde mental e economia solidária: análise das relaçóes de trabalho em uma cooperativa de confecção de Porto Alegre. Psicologia \& Sociedade, Porto Alegre, v. 18, n. 2, p. 54-61, ago. 2006. Disponível em: <http:// www.scielo.br/scielo.php?script=sci_arttext\&pid=S0102$71822006000200008 \& \operatorname{lng}=$ pt \&nrm=iso $>$. Acesso em: 25 jul. 2011. http://dx.doi.org/10.1590/ S0102-71822006000200008

BRASIL. Ministério da Saúde. Secretaria de Atenção à Saúde. Departamento de Açôes Programáticas Estratégicas. Saúde mental e economia solidária: inclusão social pelo trabalho. Brasília: Ministério da Saúde, 2005a. (Série D. Reuniōes e Conferências). Disponível em: <http:// portal.saude.gov.br/portal/arquivos/pdf/saude_mental_ economia_solidaria.pdf.>. Acesso em: 12 nov. 2009.

BRASIL. Ministério da Saúde. Secretaria de Atenção à Saúde. Departamento de Açóes Programáticas Estratégicas. Coordenação Geral de Saúde Mental. Reforma psiquiátrica e politica de saúde mental no Brasil. In: CONFERENCIA REGIONAL DE REFORMA DOS SERVIÇOS DE SAÚDE MENTAL : 15 ANOS DEPOIS DE CARACAS, 2005, Brasília. Anais... Brasília: OPAS, 2005b. Disponível em: <http://portal.saude.gov. br/portal/arquivos/pdf/relatorio_15_anos_caracas.pdf>. Acesso em: 28 jul. 2011.

BRASIL. Ministério do Trabalho e Emprego. Economia solidária: outra economia acontece: Cartilha da Campanha Nacional de Mobilização Social. Brasília: MET, SENAES, FBES, 2007.

CAYRES, C. O. et al. O desafio da reabilitaçáo profissional. In: HARARI, A.; VALENTINI, W. (Org.). A reforma psiquiátrica no cotidiano. São Paulo: Hucitec, 2001. p. 105-112.

CORTEGOSO, A. L.; CIA, F.; LUCAS, M. G. Economia Solidária: o que é e como se relaciona com a psicologia. In: CORTEGOSO, A. L.; LUCAS, M. G. (Orgs.). Psicologia e economia solidária: interfaces e perspectivas. Sáo Paulo: Casa do Psicólogo, 2008. p. 25-37.

DELGADO, P. G. Proposta de criação da Rede Nacional de Saúde mental e Economia Solidária. In: BRASIL. Ministério da Saúde. Secretaria de Atenção à Saúde. Departamento de Ações Programáticas Estratégicas. Saúde mental e economia solidária: inclusão social pelo trabalho. Brasília: Ministério da Saúde, 2005. p. 82-88. (Série D. Reuniōes e Conferências). Disponível em: <http://portal.saude.gov.br/portal/arquivos/pdf/ saude_mental_economia_solidaria.pdf. $>$. Acesso em: 12 nov. 2009.

GHIRARDI, M. I. G. Trabalho e deficiência: as cooperativas como estratégia de inclusão social. Revista de Terapia Ocupacional da Universidade de São Paulo, São Paulo, v. 15, n. 2, p. 49-54, maio/ago. 2004. Diponível em: $<$ http://www.revistasusp.sibi.usp.br/scielo.php?pid=S1415$91042004000200003 \&$ script=sci_abstract $\&$ tlng=pt $>$. Acesso em: 26 nov. 2011.

LANCMAN, S. Psicodinâmica do trabalho. In: CAVALCANTI, A.; GALVĀO, C. Terapia ocupacional: fundamentação e prática. Rio de Janeiro: Guanabara Koogan, 2007. p. 271-277.

LUSSI, I. A. O. Trabalho, reabilitação psicossocial e rede social: concepções e relações elaboradas por usuários de serviços de saúde mental envolvidos em projetos de inserção laboral. 2009. 169 f. Tese (Doutorado em Enfermagem Psiquiátrica)-Universidade de São Paulo, Ribeirão Preto, 2009. Disponível em: <http://www.teses. usp.br/teses/disponiveis/22/22131/tde-29102009-135550/>. Acesso em: 12 mar. 2010.

LUSSI, I. A. O.; PEREIRA, M. A. O. Empresa social e economia solidária: perspectivas no campo da inserção laboral de portadores de transtorno mental. Revista da Escola de Enfermagem da USP, Sáo Paulo, v. 45, n. 2, p. 515-521, abr. 2011. Disponível em: <http:// www.scielo.br/scielo.php?script $=$ sci_arttext $\&$ p id=S0080-62342011000200030>. Acesso em: 07 jul. 2011. http://dx.doi.org/10.1590/S0080-62342011000200030

MILIONI, D. B. A experiência de trabalho de usuários de um CAPS, integrantes de um empreendimento solidário: construindo vidas e possibilidades. 2009. $111 \mathrm{f}$. Dissertação (Mestrado em Enfermagem)-Universidade Federal de São Carlos, São Carlos, 2009. 
MINAYO, M. C. S. O desafio do conhecimento: pesquisa qualitativa em saúde. 7. ed. São Paulo: Hucitec; Rio de Janeiro: Abrasco, 2000.

OGAWA, R. Trabalho: liberdade versus exclusão. Revista de Terapia Ocupacional da Universidade de São Paulo, São Paulo, v. 8, n. 1, p. 49-52, jan./abr. 1997.

PACHECO, J. L. Inclusão social através do trabalho. In: CORTEGOSO, A. L.; LUCAS, M. G. (Org.). Psicologia e economia solidária: interfaces e perspectivas. São Paulo: Casa do Psicólogo, 2008. p. 219-224.

RODRIGUES, R. C.; MARINHO, T. P. C.; AMORIM, P. Reforma psiquiátrica e inclusão social pelo trabalho. Ciência e Saude Coletiva, Rio de Janeiro, v. 15, p. 1615-1626, jan./jun. 2010. Suplemento 1. Disponível em: <http://www.scielo.br/scielo.php?script=sci_ arttext\&pid=S1413-81232010000700073\&lng=pt\&nr m=iso >. Acesso em: 07 jul. 2011. http://dx.doi.org/10.1590/ S1413-81232010000700073

SARACENO, B. Libertando identidades: da reabilitação psicossocial à cidadania possível. 2. ed. Rio de Janeiro: Te Corá, Instituto Franco Basaglia, 2001a.

SARACENO, B. Reabilitação psicossocial: uma prática à espera de teoria. In: PITTA, A. M. F. (Org.). Reabilitação psicossocial no Brasil. 2. ed. São Paulo: Hucitec, 2001b. p. 150-154.

SILVA, R. A. Experiências de geração de renda e trabalho em saúde mental e agências de apoio e fomento. In: BRASIL. Ministério da Saúde. Secretaria de Atenção à Saúde. Departamento de Açôes Programáticas Estratégicas. Saúde mental e economia solidária: inclusão social pelo trabalho. Brasília, 2005. p. 53-60. (Série D. Reunióes e
Conferências). Mesa - redonda (23/11/04). Disponível em: <http://portal.saude.gov.br/portal/arquivos/pdf/ saude_mental_economia_solidaria.pdf.>. Acesso em: 12 nov. 2009.

SILVA, A. L. A.; FONSECA, R. M. G. S. Projeto copiadora do CAPS Luis Cerqueira: do trabalho de produzir coisas à produção de vida. Revista da Escola de Enfermagem da USP, São Paulo, v. 36, n. 4, p. 358-366, dez. 2002.

SINGER, P. Introdução à economia solidária. São Paulo: Editora Fundação Perseu Abramo, 2002.

SINGER, P. Economia solidária. Estudos Avançados, São Paulo, v. 22, n. 62, p. 289-314, abr. 2008. Disponível em: <http://www.scielo.br/scielo.php?pid=S0103$40142008000100020 \&$ script $=s c i \_$arttext $>$. Acesso em: 27 julho. 2011. http://dx.doi.org/10.1590/ S0103-40142008000100020

TAGLIAFERRO, P. Enfrentando desafios e construindo possibilidades: A experiência da equipe no processo de incubação de um empreendimento solidário formado por usuários de um CAPS. 2011. 165 f. Dissertação (Mestrado em Enfermagem)-Universidade Federal de São Carlos, São Carlos, 2011. Disponível em: <http://www. bdtd.ufscar.br/htdocs/tedeSimplificado/tde_arquivos/26/ TDE-2011-04-11T160352Z-3613/Retido/3522.pdf>. Acesso em: 28 nov. 2011.

TOLFO, S. R.; PICCININI, V. Sentidos e significados do trabalho: explorando conceitos, variáveis e estudos empíricos brasileiros. Psicologia \& Sociedade, Porto Alegre, v. 19, p. 38-46, 2007. Número especial. Disponível em <http://www.scielo.br/scielo.php?script=sci_ arttext\&pid=S0102-71822007000400007\&lng=pt\&n rm=iso >. Acesso em: 25 jul. 2011.

\section{Contribuição dos Autores}

Isabela Aparecida de Oliveira Lussi: Contribuiu na concepção do trabalho, na análise dos dados e na elaboração e redaçáo do texto. Giovana Garcia Morato: Contribuiu na coleta e organizaçáo dos dados, na sua análise e na elaboração e redação do texto.

\section{Notas}

${ }^{1}$ Trabalho oriundo de Pesquisa de Iniciação Científica com financiamento da Fundação de Amparo à Pesquisa do Estado de São Paulo (FAPESP). A pesquisa foi submetida e aprovada pelo Comitê de Ética em Pesquisa em Seres Humanos da UFSCar, sob o parecer n. 200/2011. Trabalho apresentado no XIX Congresso de Iniciação Científica da UFSCar, realizado entre 26 e 30 de setembro de 2011, e no XII Congresso Brasileiro de Terapia Ocupacional e IX Congresso Latino Americano de Terapia Ocupacional, realizado no período de 11 a 14 de outubro de 2011. 